\title{
The core features of CSCL: Social situation, collaborative knowledge processes and their design
}

\author{
Ulrike Cress $^{1}$ - Gerry Stahl ${ }^{2} \cdot$ Sten Ludvigsen $^{3}$ • \\ Nancy Law ${ }^{4}$
}

Published online: 13 May 2015

(C) International Society of the Learning Sciences, Inc. 2015

The four articles presented in this issue cover a broad spectrum of topics: the hierarchy of learners, different forms of awareness, group composition and classroom orchestration. The learning contexts also differ significantly, considering collaborative learning in university courses, in organizational e-learning and in vocational training. Accordingly, the student actions and interactions that the different settings aim to induce vary strongly (but return to themes in previous articles): sending and answering requests (Wise et al. 2014), building knowledge using Knowledge Forum (Zhao and Chan 2014) or creating tangible artifacts (Damsa 2014).

Even though the surface structures of the four articles are quite different, they all contribute to understanding core underlying topics of CSCL: the influence of social aspects of the collaboration scenario, the type of learning that takes place in collaborative groups and the design of collaborative learning processes.

\section{The influence of the social situation}

This issue concerns how the social aspects of the collaborative situation influence collaboration and learning. It considers qualities of the group that the learners are part of, but also

Gerry Stahl

Gerry@ijCSCL.org

Ulrike Cress

Ulrike@ijCSCL.org

Sten Ludvigsen

Sten@ijCSCL.org

Nancy Law

Nancy@ijCSCL.org

1 Leibniz-Institut für Wissensmedien, Tübingen, Germany

2 Drexel University, Philadelphia, PA, USA

3 University of Oslo, Oslo, Norway

4 University of Hong Kong, Hong Kong, China 
characteristics of the group's members. In CSCL, the interaction between group members is generally mediated through a technical tool. This tool communicates cues about the members and the group. The social cues that the CSCL tool delivers can be at least as influential as the objective features of the social situation.

In the 1980s, when computers first became common means of communication, research on "computer-mediated communication" (CMC) mainly regarded its differences from face-toface communication (e.g., Kiesler et al. 1984). Early theories assumed that CMC would be deficient, because - compared to direct communication - it would only deliver a limited subset of social cues. For example, if communication partners communicate via text messages, they cannot see each other; this visual anonymity was expected to influence people's interaction negatively.

Later on, research in CMC observed that computer mediation need not necessarily be a hindrance for collaboration. Even the anonymity that may result from remote communication can be seen to be a means to overcoming problems inherent in socially richer face-to face communication situations (Spears and Lea 1994; Walter 1996). For instance, in face-to-face situations people of low status contribute less than those of high status and their contributions do not attract the same amount of attention as those from high-status people. A computermediated scenario that hides participants' identity provides low-status participants a higher chance to be equally involved and as influential as high status participants (Sproull and Kielser 1986).

It was also found that in anonymous situations group members can develop an even stronger group identity than in non-anonymous face-to-face situations (Cress 2005; Postmes et al. 2001). This is the case because anonymity can hide the fact that the group members may be quite heterogeneous. If communication takes place in a scenario where others are not visually present in person, an individual may focus more on the group as a whole instead of on its single members. If individuals interact without seeing each other, they may develop a stronger group identity and behave more as group members than as individuals (Reicher 1984).

In contrast to the view that computer mediation provides a socially impoverished environment (where social context cues are filtered out), research in CSCL assumes that mediational tools may also offer social enhancements to the interaction. For example, some technical tools can make cues visible that would not be visible in non-mediated interactions. Many such possibilities are included within the notion of "awareness tools." These tools may present information about the social situation or about the group members, which would not be available in normal, non-mediated communication (Buder 2011). For example, such tools can provide information about characteristics of people, such as their knowledge, activities, expertise, social status or social relations. They can even present this information in an aggregated way that makes particular conclusions salient. An awareness tool can provide information about peers' activity levels or recommend suitable learning partners.

\section{Differentiating the type of learning that takes place in collaborative groups}

Probably the most important aspect of CSCL research is the detailed analysis of interaction processes and the learning that takes place during collaborative activities. Collaboration, as it is understood in CSCL (Dillenbourg 1999), is much more than just communication between individuals, contributing information to each other, exchanging ideas, or coordinating activities 
to reach individual or shared goals. It is more specific than just a general benefit of individuals learning from each other. CSCL is especially interested in situations where people do not just exchange information, but jointly create something new, which could be new knowledge or understanding that none of the participants had before. Joint meaning making and constructing new knowledge can be regarded as a kind of gold standard in CSCL.

Group cognition (Stahl 2006) is achieved when the group not only brings different people together, where the members may or may not benefit from some other members, but when the group as a whole starts to make meaning, develops collective cognitive responsibility (Zhang et al. 2009) or creates new knowledge (Cress and Kimmerle 2008; van Aalst 2009). CSCL has the vision that being in a group can not only empower individual learning and performance, but can also enable emergent meaning-making processes at the group unit of analysis (Oeberst et al. 2014; Stahl 2013).

CSCL aims not only to show that learning in a group is efficient - as research in cooperative learning has done for many years (Johnson and Johnson 1999; Slavin 1980). It also aims to demonstrate that the group interaction has a learning or knowledge-constructing effect. This is why CSCL studies go beyond comparing learning in different collaborative situations and try to find out what kind of learning takes place, and how exactly a group benefits from the activities and interactions of its members.

Microanalysis and ethnomethodology can be useful approaches for understanding processes underlying learner outcomes and production of knowledge artifacts. It is not easy to quantify and predict the pivotal moments when collaborative knowledge creation or collaborative meaning making really happen (Law and Wong 2013; Suthers et al. 2013). It still seems to be a "magic" moment (Roschelle and Teasley 1995) when such a pivotal process of shared meaning making takes place. Current research in CSCL shows that we may identify such events in retrospect, but we are far away from understanding how they happen or reliably predicting them. They remain rare, poorly understood and unpredictable.

\section{Designing computer support for collaborative learning}

A central aim of CSCL research is to generate situations that make collaborative learning effective and to enhance the probability that emergent processes may take place. Consequently, a core activity of CSCL research is to design adequate CSCL tools and settings. How can activities of deep learning and effective interaction be best induced? Which learning materials can stimulate such processes? What kinds of collaboration scripts are needed (Fischer et al. 2006)? How can learning at individual, small-group and classroom levels be orchestrated to support each other fluidly (Dillenbourg 2013)?

Several approaches may be mentioned here: The knowledge building theory (Scardamalia and Bereiter 2014) envisions that learners would collectively build knowledge through taking collective responsibility to improve their understanding of authentic problems. The Knowledge Forum software was designed as a discourse tool that scaffolds learners' sharing of ideas, structures the process of critical evaluation, refinement or improvement of ideas, as well as supports the construction of rise-above summaries or the identification of problems of understanding.

Scripting emerged as a necessity in situations where self-regulation of the learning process needs increased external guidance and structure (Fischer et al. 2006; Kobbe et al. 2007). 
Scripts assign roles and responsibilities to the learners, coordinate their activities and give implicit instructions. Thus, scripts structure the social situation as well as the learning process.

The construction of artifacts (Kafai and Resnick 1996; Stahl et al. 2014) was seen as a possibility to ensure that knowledge exchange does not remain abstract, but also comprises practical and tacit knowledge. Collaboratively working on such artifacts enables natural forms of internalization and externalization, which are essential mechanisms of interpersonal learning (Kimmerle et al. 2015; Tee and Lee 2013). However, we have found that the use of wellestablished CSCL tools and environments alone does not guarantee that collective knowledge construction will take place (Overdijk et al. 2014).

\section{How the four articles of this issue contribute to these core concerns in CSCL}

In the following sections, we do not intend to provide summaries of the studies in exactly the way they were presented by the authors. Instead, we try to relate the four studies to the above mentioned core topics in CSCL and ask what each study can contribute to these aspects.

\section{Hierarchical positions}

The article by Martin Rhem, Wim Gijselaers and Mien Segers deals with the impact of hierarchical positions on communities of learning. It contributes to our understanding of how the characteristics of group members influences collaborative learning interactions. The authors provide an empirical analysis of a field setting in which an organization's members interact in an organizational-learning setting. The authors find the effects they expected: Participants in the higher hierarchy positions were more active and had better learning performances than those at a lower level.

A surprising result of their study is revealed by a cluster analysis that identifies different clusters of learners: As expected, three groups are determined by the different hierarchy levels (low, medium, high) and their activity pattern is consistent with their hierarchical status. Interestingly the study identifies a fourth group, consisting of the most active participants. These were the drivers of the learning communities, as their agency directed the groups' activities. They authored the most contributions and those with the highest quality. Half of the members in this group were from a high and the other half from a low position in the hierarchy. This second half is the interesting group. They were highly active and valuable leaders in the learning communities - despite their low hierarchical level.

The study reveals a correlation that probably does not result from a causal effect. It might even be expected that people of higher hierarchical positions are more active and more dominant in general. Therefore, it is natural that they also take over the leadership in their learning communities. However, it remains unclear what enables and motivates some low-status members to take over the lead. Are these people who would in principle have leadership qualities, but did not have an adequate career? Does the online setting give them a chance to be more active and to become leaders? What would have been the situation if the collaboration did not take place in a remote e-learning setting, but in a faceto-face scenario? We do not know the answers, but it would be worthwhile to research it. What factors in these learning communities helped at least single learners unfold their leadership potential? 
An interesting finding of the study, which is reported more marginally, is the fact that no group effects were found. The non-significant intra-group correlation seems to express that the different groups did not have any specific influence on people's learning and performance. A leader may unfold leadership potential in any group, independent of the group composition. Is this a hint that group composition and the social influence of being in a special group is not as high as we might expect in CSCL? Are such social influences perhaps negligible compared to the characteristics of the single learner? Is this due to the special social setting that was chosen or is this a more general finding? These questions refer to the core of CSCL when it comes to analyzing the influence of the social setting on CSCL.

\section{Social awareness and knowledge awareness}

The second article, by Jian-Wei Lin, Li-Jung Mai and Yuan-Cheng La, compares the influence of two forms of awareness: social awareness and knowledge awareness. Both were quite commonly researched in earlier CSCL research, but their effect has not been compared directly. The reported study finds that social awareness had much greater effects than knowledge awareness. Especially over time, it unfolded its influence. Social awareness stimulated peer interaction, led to denser networks and resulted in more social connections among group members. It also resulted in better performance of the individual learners. This is interesting because one might have expected that the awareness of others' knowledge can help a learner to find the best partner who can complement the learner's own knowledge optimally. Therefore, it is surprising that the social aspect of others' activities and social relations has a stronger effect (even on performance) than the knowledge about others' expertise. We may ask if this is a result of how the study operationalized both forms of awareness or if it is generalizable to other situations.

This study also leads to interesting questions for future research: What kind of collaboration and learning take place? When learners provided with social awareness perform better in a knowledge test than learners provided with knowledge awareness, does this also mean that learning is more efficient at the level of the group? Did the different types of awareness have an effect on people's interaction, on group cognition and knowledge construction? Was the learning discourse different across the two conditions?

\section{Fixed and opportunistic grouping}

The study by Tuya Siqin, Jan van Aalst and Samuel Kai Wah Chu about the effect of fixed group vs. opportunistic collaboration tries to answer the kinds of questions raised with regard to the last study. In the fixed-group condition, learners were organized in small groups, where five learners were randomly assigned to a group in order to complete certain tasks. In the opportunistic-collaboration condition, in contrast, learners individually and explicitly decided about the partners they wanted to collaborate with for a particular problem. They disbanded the group when the problem had been solved and flexibly formed new groups to achieve subsequent goals.

In order to compare the two conditions, the authors apply a multi-faceted analysis. They consider quantitative features of participation and interactivity as well as the content of the dialogs and the quality of knowledge construction that took place in the groups. The authors 
differentiate between knowledge sharing, knowledge construction and knowledge creation (van Aalst 2009). It is interesting that they do not find any knowledge creation at all in any group. The majority of interactions are coded as knowledge sharing (where knowledge was just accumulated), about one third as knowledge construction (where the group got a deeper understanding of a focal problem), but no activity shows knowledge creation (where understanding took place, beyond what was already known in the group). This is the case for both types of groups.

The rarity of knowledge creation is an important result, which has also been found in other CSCL research and that needs to be acknowledged. Even if CSCL environments have the ideal goal of supporting learners to effectively create knowledge, this appears to be a rare occurrence. It remains an ideal that does not take place frequently, and if it takes place, it may not be measured easily. May this be because deep learning in groups needs time to happen? Groups must interact for an extended period to develop effective group practices for collaboration and knowledge construction within a classroom climate that values and nurtures knowledge building (Ritella and Hakkarainen 2012; Stahl 2015)? Even then, it may be a serendipitous result, situated in the unique discourse of students working together in a structured educational setting (Hakkarainen 2009; Hakkarainen and Lipponen 2002), which makes it difficult to predict.

\section{Classroom orchestration using tabletops}

The article by Sebastien Cuendet, Jessica Dehler-Zufferey, Giulia Ortoleva and Pierre Dillenbourg on an integrated way to orchestrate tangible user interfaces in a classroom addresses aspects of designing effective environments and orchestrating classroom activities. The knowledge domain is vocational training for carpenters. The design of the environment is based on detailed studies of how carpenters do their work, in order to minimize the problems of tacit knowledge and of weak knowledge transfer between school and work.

The learning setting involves a tangible user interface called TaraCarp. This top-down camera-projector tabletop system combines real and virtual artifacts. The tabletop is also used as a tool for scripting the collaboration (Dillenbourg and Evans 2011; Dillenbourg and Hong 2008). First, each student has to cut an object virtually on the tabletop and print the developed plan. After having critically reflected and improved on their own individual plans, the apprentices have to pair up and exchange their plans. Each one then marks out a real block and cuts it according to the plan of the other learner. The two apprentices are then brought together to compare the objects. The tabletops are used not only as part of the tangible interfaces, but also as orchestration tools for the teacher.

The study is a great example of how CSCL can combine work on real and virtual artifacts, how it can structure collaboration and make the complex situation manageable in a classroom. Further studies with this setting could perhaps make clear, how exactly the students benefit from the collaboration. Does the collaboration in dyads have specific effects? Can we trace the interpersonal knowledge transfer of practical knowledge? Does the collaboration just have a motivational effect or can we also identify a more specific effect on the types of learning that take place in such a practical setting? As the article shows, tangible interfaces may provide interesting and innovative means for CSCL that lead to new questions about the nature of what students can learn through collaboration and what kind of knowledge is shared or created. 


\section{CSCL 2015}

The four articles in this second issue of 2015 contribute to furthering our understanding of CSCL. They raise highly relevant questions about the social nature of collaborative learning, about the kind of knowledge that is collaboratively constructed in a group and about how we can use technical tools to structure or design ongoing social and knowledge-related processes for learning. They also show that the goal of collaboration to improve understanding and to construct new knowledge is not easy to achieve.

The theme of the upcoming 11th Conference on Computer-Supported Collaborative Learning that will take place in Gothenburg is "Exploring the Material Conditions of Learning: Opportunities and Challenges for CSCL." This may direct our attention to further aspects of collaboration and learning-how social, cognitive and collaborative processes are structured through artifacts, affordances and forces associated with the sociotechnical environment in CSCL.

\section{References}

Buder, J. (2011). Group awareness tools for learning: Current and future directions. Computers in Human Behavior, 27, 1114-1117.

Cress, U. (2005). Ambivalent effect of member portraits in virtual groups. Journal of Computer-Assisted Learning, 21, 281-291.

Cress, U., \& Kimmerle, J. (2008). A systemic and cognitive view on collaborative knowledge building with wikis. International Journal of Computer-Supported Collaborative Learning, 3(2), 105-122.

Damsa, C. I. (2014). The multi-layered nature of small-group learning: Productive interactions in object-oriented collaboration. International Journal of Computer-Supported Collaborative Learning, 9(3), $247-281$.

Dillenbourg, P. (1999). What do you mean by “collaborative learning”? In P. Dillenbourg (Ed.), Collaborative learning: Cognitive and computational approaches (pp. 1-16). Amsterdam: Pergamon, Elsevier Science.

Dillenbourg, P. (2013). Design for classroom orchestration. Unpublished manuscript. Web: http://www. academia.edu/2863702/_Design_for_Classroom_Orchestration_position_paper.

Dillenbourg, P., \& Evans, $\bar{M}$. (2011). Interactive tabletops in education. International Journal of ComputerSupported Collaborative Learning, 6(4), 491-514.

Dillenbourg, P., \& Hong, F. (2008). The mechanics of CSCL macro scripts. International Journal of ComputerSupported Collaborative Learning, 3(1), 5-23.

Fischer, F., Mandl, H., Haake, J., \& Kollar, I. (2006). Scripting computer-supported collaborative learning: Cognitive, computational and educational perspectives. In Computer-supported collaborative learning book series, vol 6. Dordrecht: Kluwer Academic Publishers.

Hakkarainen, K. (2009). A knowledge-practice perspective on technology-mediated learning. International Journal of Computer-Supported Collaborative Learning, 4(2), 213-231.

Hakkarainen, K., \& Lipponen, L. (2002). Epistemology of inquiry and computer-supported collaborative learning. In T. Koschmann, R. Hall, \& N. Miyake (Eds.), Cscl2: Carrying forward the conversation (pp. 129-156). Mahwah: Lawrence Erlbaum Associates.

Johnson, D. W., \& Johnson, R. T. (1999). Making cooperative learning work. Theory Into Practice, 38, 67-73.

Kafai, J., \& Resnick, M. (1996). Constructionism in practice: Designing, thinking, and learning in a digital world. New York: Routledge.

Kiesler, S., Siegel, J., \& McGuire, T. W. (1984). Social psychological aspects of computer-mediated communication. American Psychologist, 39, 1123-1134.

Kimmerle, J., Moskaliuk, J., Oeberst, A., \& Cress, U. (2015). Learning and collective knowledge construction with social media: a process-oriented perspective. Educational Psychologist.

Kobbe, L., Weinberger, A., Dillenbourg, P., Harrer, A., Hamalainen, R., Hakkinen, P., et al. (2007). Specifying computer-supported collaboration scripts. International Journal of Computer-Supported Collaborative Learning, 2(2-3), 211-224.

Law, N., \& Wong, O. W. (2013). Exploring pivotal moments in students' knowledge building progress using participation and discourse marker indicators as heuristic guides. In D. D. Suthers, K. Lund, C. Penstein 
Rosé, C. Teplovs, \& N. Law (Eds.), Productive multivocality in the analysis of group interactions (pp. 397415). New York: Springer.

Oeberst, A., Halatchliyski, I., Kimmerle, J., \& Cress, U. (2014). Knowledge construction in Wikipedia: A systemic-constructivist analysis. Journal of the Learning Sciences, 23, 149-176.

Overdijk, M., van Diggelen, W., Andriessen, J., \& Kirschner, P. A. (2014). How to bring a technical artifact into use: A micro-developmental perspective. International Journal of Computer-Supported Collaborative Learning, 9(3), 283-303.

Postmes, T., Spears, R., Sakhel, K., \& deGroot, D. (2001). Social influence in computer-mediated communication: The effects of anonymity on group behavior. Personality and Social Psychology Bulletin, 27, 12431254.

Reicher, S. D. (1984). Social influence in the crowed: Attitudinal and behavioural effects of de-individuation in conditions of high and low group salience. British Journal of Social Psychology, 23, 341-450.

Ritella, G., \& Hakkarainen, K. (2012). Instrumental genesis in technology-mediated learning: From double stimulation to expansive knowledge practices. International Journal of Computer-Supported Collaborative Learning, 7(2), 239-258.

Roschelle, J., \& Teasley, S. (1995). The construction of shared knowledge in collaborative problem solving. In C. O’Malley (Ed.), Computer-supported collaborative learning (pp. 69-197). Berlin: Springer Verlag.

Scardamalia, M., \& Bereiter, C. (2014). Knowledge building and knowledge creation: Theory, pedagogy and technology. In K. Sawyer (Ed.), Cambridge handbook of the learning sciences (2nd ed.). Cambridge: Cambridge University Press.

Slavin, R. (1980). Cooperative learning. Review of Educational Research, 50(2), 315-342.

Spears, R., \& Lea, M. (1994). Panacea or panopticon? The hidden power in computer-mediated communication. Communication Research, 427-459.

Sproull, L., \& Kielser, S. (1986). Reducing social contet cues: Electornic mail in organizational communication. Management Science, 32, 1492-1512.

Stahl, G. (2006). Group cognition: Computer support for building collaborative knowledge. Cambridge: MIT Press. Web: http://GerryStahl.net/elibrary/gc.: http://mitpress.mit.edu/books/group-cognition.

Stahl, G. (2013). Translating Euclid: Designing a human-centered mathematics. San Rafael: Morgan \& Claypool Publishers. doi:10.2200/S00492ED1V01Y201303HCI017. Web: http://GerryStahl.net/elibrary/ euclid.

Stahl, G. (2015). Constructing dynamic triangles together: The development of mathematical group cognition. Cambridge: Cambridge University Press. Web: http://GerryStahl.net/elibrary/analysis.

Stahl, G., Ludvigsen, S., Law, N., \& Cress, U. (2014). CSCL artifacts. International Journal of ComputerSupported Collaborative Learning, 9(3), 237-245.

Suthers, D. D., Lund, K., Rosé, C. P., Teplovs, C., \& Law, N. (Eds.). (2013). Productive multivocality in the analysis of group interactions. New York: Springer. doi:10.1007/978-1-4614-8960-3.

Tee, M. Y., \& Lee, S. S. (2013). Advancing understanding using nonaka's model of knowledge creation and problem-based learning. International Journal of Computer-Supported Collaborative Learning, 8(3), 313331.

van Aalst, J. (2009). Distinguishing knowledge-sharing, knowledge-construction, and knowledge-creation discourses. International Journal of Computer-Supported Collaborative Learning, 4(3), 259-287.

Walter, J. B. (1996). Computer-mediated communication - impersonal, interpersonal, and hyperpersonal interaction. Communication Research, 23, 3-43.

Wise, A. F., Hausknecht, S. N., \& Zhao, Y. T. (2014). Attending to others' posts in asynchronous discussions: Learners' online "listening" and its relationship to speaking. International Journal of Computer-Supported Collaborative Learning, 9(2), 185-209.

Zhang, J., Scardamalia, M., Reeve, R., \& Messina, R. (2009). Designs for collective cognitive responsibility in knowledge-building communities. Journal of the Learning Sciences, 18

Zhao, K., \& Chan, C. K. K. (2014). Fostering collective and individual learning through knowledge building. International Journal of Computer-Supported Collaborative Learning, 9(1), 63-95. 